\title{
DA SAUDADE DA TERRA NATAL ÀS CIDADES INVISÍVEIS: ENTRE RESTAURAÇÃO E PRODUÇÃO DE CIDADES SUBJETIVAS
}

\author{
Ivan Rubens Dário $\mathrm{Jr}^{1}$ \\ Romualdo Dias ${ }^{2}$
}

\begin{abstract}
Resumo
Analisamos, em pesquisa de mestrado, nossa experiência na coordenação do Orçamento Participativo na cidade de Suzano/SP no período entre 2005 e 2008. Optamos pela cartografia como metodologia adequada para captar movimentos e paisagens durante esse trânsito no território da cidade onde sujeito e cidade se produziam em mútua implicação. Neste artigo, nosso foco está na temática da cidade presente no capítulo teórico de nossa dissertação, seguindo no seguinte percurso: aceitando uma provocação de Michel Foucault, iniciamos com uma rápida introdução, trazemos a saudade da terra natal presente na música popular brasileira, na literatura de Ítalo Calvino e a leitura artística nas cores de Lutero Pröschold, para dialogar com as teorias de Félix Guattari, Yi-fu Tuan, David Harvey, Luc Boltanski e Ėve Chiapello. Apresentamos uma cidade mulher e seguimos para as considerações finais.
\end{abstract}

Palavras - chave: cidade - subjetividade - território - movimento - experiência

\section{La nostalgie de la patrie vers les villes invisibles: entre la restauration et de la production des villes subjectives}

\begin{abstract}
Résumé
Analysé dans la recherche de maître, notre expérience dans la coordination du budget participatif dans la ville de Suzano / SP dans la période entre 2005 et 2008. Nous avons choisi la cartographie comme méthodologie appropriée pour capturer des mouvements et des paysages pendant le transport dans la ville où est le sujet et la ville produit en implication mutuelle. Dans cet article, nous mettons l'accent sur le thème de la ville présente dans le chapitre théorique de notre mémoire, suivant l'itinéraire suivant: accepter un défi de Michel Foucault, a commencé par une brève introduction, nous apportons la terre de la nostalgie de Noël présent dans la musique populaire brésilienne, la littérature Italo Calvino et la lecture artistique aux couleurs de Luther Pröschold au dialogue avec la théorie de Felix Guattari, Yi-fu Tuan, David Harvey, Luc Boltanski et Eve Chiapello. Ici, une ville de la femme et nous sommes allés aux considérations finales.
\end{abstract}

Mots-clés: ville - subjectivité - territoire - mouvement - expérience

\footnotetext{
1 Mestre em educação pela Universidade Estadual Paulista - UNESP campus Rio Claro/SP. Email: ivanrubens@hotmail.com.br

${ }^{2}$ Professor da Universidade Estadual Paulista - UNESP campus Rio Claro/SP.E-mail: diasro@terra.com.br Estudos Geográficos, Rio Claro, 15(1): 44-61, jan./jun. 2017 (ISSN 1678-698X) http://www.periodicos.rc.biblioteca.unesp.br/index.php/estgeo
} 
Há momentos na vida em que a questão de saber se podemos pensar diferentemente do que pensamos, e perceber diferentemente do que vemos, é absolutamente necessária se quisermos continuar de algum modo a olhar e refletir. Michel Foucault

\section{Introdução}

Em nossa dissertação de mestrado $^{3}$, analisamos a implementação do Orçamento Participativo (OP) na cidade de Suzano/SP, região metropolitana de São Paulo capital, uma experiência singular. Optamos pela cartografia como metodologia adequada para captar os movimentos e as paisagens durante o trânsito no território da cidade. Para realização do conjunto das ações, a cidade foi organizada em doze regiões e, para cada região, reuniões preparatórias às dezenas antecediam a Plenária Regional Deliberativa anual, e um intenso trabalho com Conselho do Orçamento Participativo, o CORPO, que reunia trinta e dois conselheiros, sendo vinte e quatro eleitos diretamente nas plenárias e oito indicados pelo governo, no período compreendido entre 2005 e 2008. Organizamos nossa dissertação num primeiro capítulo de caráter empírico, um segundo capítulo de caráter teórico e um terceiro capítulo de caráter analítico no esforço de registrar os saberes produzidos nesse trânsito pelo território físico da cidade e, ao mesmo tempo, por territórios subjetivos. Mas também no trânsito por territórios existenciais que produzem sentidos outros, onde o pensamento movimenta, circula, dança, canta. A mútua implicação entre processos educacionais e processos de subjetivação. Essa experiência nos permitiu intensos encontros e o convívio com um povo migrante, trabalhador, com sua riqueza cultural.

Neste artigo, nosso foco estará na temática da cidade presente na discussão teórica de nossa dissertação. Muito presente na cultura popular, iniciaremos com o cancioneiro popular trazendo a saudade da terra natal; com a literatura de Ítalo Calvino e a leitura plástica de Lutero Pröschold, para dialogar com autores como Félix Guattari, Yi-fu Tuan, David Harvey, Luc Boltanski e Ėve Chiapello.

\section{Saudade da terra natal no cancioneiro popular}

Durante a leitura de Topofilia: um estudo sobre a percepção, atitudes e valores do meio ambiente, como diz o compositor Chico Buarque na canção Mar e Lua (que, de alguma maneira traça um paralelo entre vida e rio), fomos correnteza abaixo rolando no leito, virando peixes, conchas, seixos, areias. Percebemos outros tantos olhares para a cidade, possibilidades outras de senti-la, de pensar a cidade e, desta maneira, nos demos conta de que uma cidade é muitas e tantas, razão pela qual procuramos um pouco na cultura popular alguns sinais de significação das cidades.

Nosso cancioneiro popular é rico na temática da saudade e, neste particular, da saudade da terra natal. Vejamos algumas canções populares que falam do movimento das pessoas no território, da migração, das relações construídas e dos sentimentos vividos neste trânsito sobre o chão.

\footnotetext{
${ }^{3}$ CORPO em movimento: marcas do Orçamento Participativo na cidade de Suzano/SP, disponível em < http://repositorio.unesp.br/handle/11449/142810> acesso em 24/12/2016.

Estudos Geográficos, Rio Claro, 15(1): 44-61, jan./jun. 2017 (ISSN 1678-698X)

http://www.periodicos.rc.biblioteca.unesp.br/index.php/estgeo
} 
O cantor, compositor e sanfoneiro Luiz Gonzaga, conhecido como o rei do baião, percorreu todo o território brasileiro com sua arte. Na canção Pau de Arara ${ }^{4}$ ele fala de um retirante que deixa a cidade de Bodocó, também no sertão pernambucano, carregando poucas coisas.

Quando eu vim do sertão,

Seu môço, do meu Bodocó

A maleta era um saco

E o cadeado era um nó

Só trazia a coragem e a cara

Viajando num pau-de-arara

Eu penei, mas aqui cheguei

Trouxe um triângulo, no matolão

Trouxe um gonguê, no matolão

Trouxe um zabumba dentro do matolão

Xóte, maracatu e baião

Tudo isso eu trouxe no meu matolão

A canção Cuitelinho ${ }^{5}$, de domínio público, tem origem no folclore do Pantanal Matogrossense. Trata-se da história de um brasileiro que, tornado soldado, lutou na guerra do Paraguai.

Cheguei na beira do porto onde as ondas se espaia

As garça da meia-volta e senta na beira da praia

E o cuitelinho não gosta, que o botão de rosa caia

Ai quando eu vim da minha terra despedir da parentaia

Eu entrei no Mato Grosso bem em terras Paraguaias

La tinha revolução, enfrentei forte bataia

A tua saudade corta como aço de navaia

O coração fica afrito, bate uma e a outra faia

E o zoio se enchem d'água que até a vista se atrapaia

A canção Saudade da Minha Terra ${ }^{6}$ conta com detalhes a saga de um migrante que se despede de uma moça paulista para retornar ao sertão. Cansado do sofrimento na cidade, retorna à terra natal para morrer onde nasceu, e onde 'descansam' seus ancestrais.

De que me adianta viver na cidade

Se a felicidade não me acompanhar

Adeus, paulistinha do meu coração

Lá pro meu sertão quero voltar [...]

A canção Lampião de gás fala da saudade da infância vivida num quintal da rua da graça; Luar do sertão ${ }^{8}$ fala da escuridão de uma cidade em comparação com

\footnotetext{
${ }^{4}$ De Luiz Gonzaga (Exu/PE 1912 - 1989, Recife/PE).

${ }^{5}$ Segundo consta, a letra foi recolhida por Paulo Vanzolini, zoólogo e compositor paulista, durante uma pescaria. Ele ainda acrescentou o seguinte verso: "Eu vou pegar seu retratinho e colocar numa medalha. Com seu vestidinho branco e um laço de cambráia. Pendurá-la em meu peito. Onde o coração trabaia ia ia".

${ }^{6}$ Isidoro Castro de Assumpção, (Vigia/PA, 1858 - Belém/PA, 1925). Durante muito tempo foi desconhecida a autoria.

${ }_{7}^{7}$ De Zica Bergami (Ibitinga/SP 1913-2011, São Paulo/SP), em parceria com Hervê Cordovil, canção de 1957.

8 De Catulo da Paixão Cearense (São Luiz/MA, 1863-1946), em parceria com João Pernambuco, canção da primeira década do século XX, provavelmente de 1914.
}

Estudos Geográficos, Rio Claro, 15(1): 44-61, jan./jun. 2017 (ISSN 1678-698X)

http://www.periodicos.rc.biblioteca.unesp.br/index.php/estgeo 
claridade (que até parece um sol de prata) do luar do sertão; Em Tristeza do Jeca ${ }^{9}$ a viola e a cantoria são o remédio para curar a dor da saudade da serra e do ranchinho à beira chão. Esta canção termina assim:

Vou parar cua minha viola já não posso mais chorar

Pois um jeca quando canta tem vontade de chorar

O choro que vai caindo

Devagar vai se sumindo

Como as águas vão para o mar

Em Lamento Sertanejo ${ }^{10}$, o modo de viver na cidade para quem é do sertão tem sua particularidade: "eu quase não saio, eu quase não tenho amigo, eu quase que não consigo ficar na cidade sem viver contrariado". A canção No Rancho Fundo $^{11}$, também conta uma história de saudade, mas percebe-se uma inversão. Os passeios pela cidade, os encontros na cidade, esse trânsito, tudo isso ampliou a visão de mundo do moreno, o personagem da canção. "Ele que era o cantor da primavera e que fez do rancho fundo o céu melhor que tem no mundo". Contudo, o rancho e tudo aquilo perdeu o sentido. E o próprio moreno também mudou, ele não era mais o mesmo depois de sua experiência urbana.

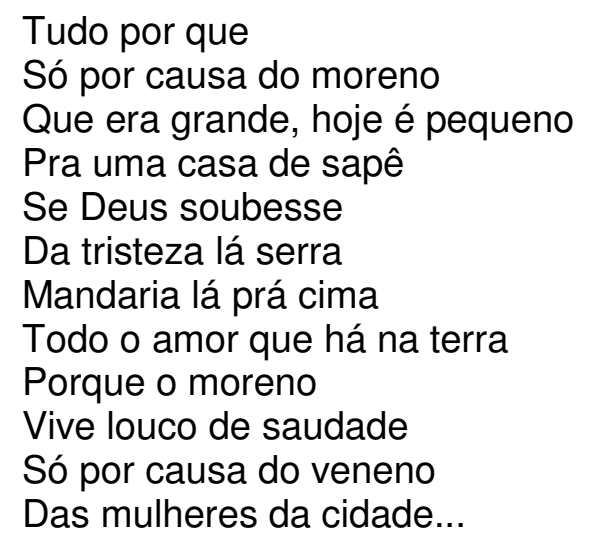

Trabalhamos com algumas canções no sentido de explorar um pouco essa maneira de dar linguagem para um sentimento, essa espécie de afeto que o migrante carrega consigo durante toda sua vida, uma espécie de saudade de um tempo e espaço, de uma infância cuja materialidade aconteceu num quintal, numa serra, num ranchinho, no Mato Grosso, em Bodocó, no sertão, enfim, numa terra natal. Essa memória parece determinante nas significações das cidades no curso da vida. Passemos então para a literatura.

\section{Literatura e leitura plástica: as cidades invisíveis}

No livro As cidades Invisíveis de Ítalo Calvino, o viajante veneziano Marco Polo descreve para Kublai Khan as incontáveis cidades do imenso império do conquistador mongol. Lutero Pröscholdt é mais um brasileiro, artista e arquiteto. Seu

\footnotetext{
${ }^{9}$ De Angelino de Oliveira (Itaporanga/SP 1888-1964, São Paulo/SP). Canção da segunda década do século XX.

${ }^{10}$ Lamento Sertanejo, letra de Gilberto Gil (Salvador/BA, 1942) e música de Dominguinhos (José Domingos de Moraes, Garanhuns/PE 1941-2013, São Paulo/SP).

${ }_{11}$ De Ary Barroso (Ubá/MG 1903 - 1964, Rio de Janeiro/RJ) e Lamartine Babo (Rio de Janeiro 1904 - 1963), canção de 1931.
}

Estudos Geográficos, Rio Claro, 15(1): 44-61, jan./jun. 2017 (ISSN 1678-698X)

http://www.periodicos.rc.biblioteca.unesp.br/index.php/estgeo 
trabalho está disponível na rede mundial de computadores e se chama Cidades Invisíveis. As telas de Lutero nos ajudam a pensar com Ítalo Calvino. Ambos nos ajudam a pensar com Félix Guattari, como veremos mais à diante. Vejamos algumas cidades invisíveis: Isaura, Ândria e Diomira.

Figura 1. Isaura

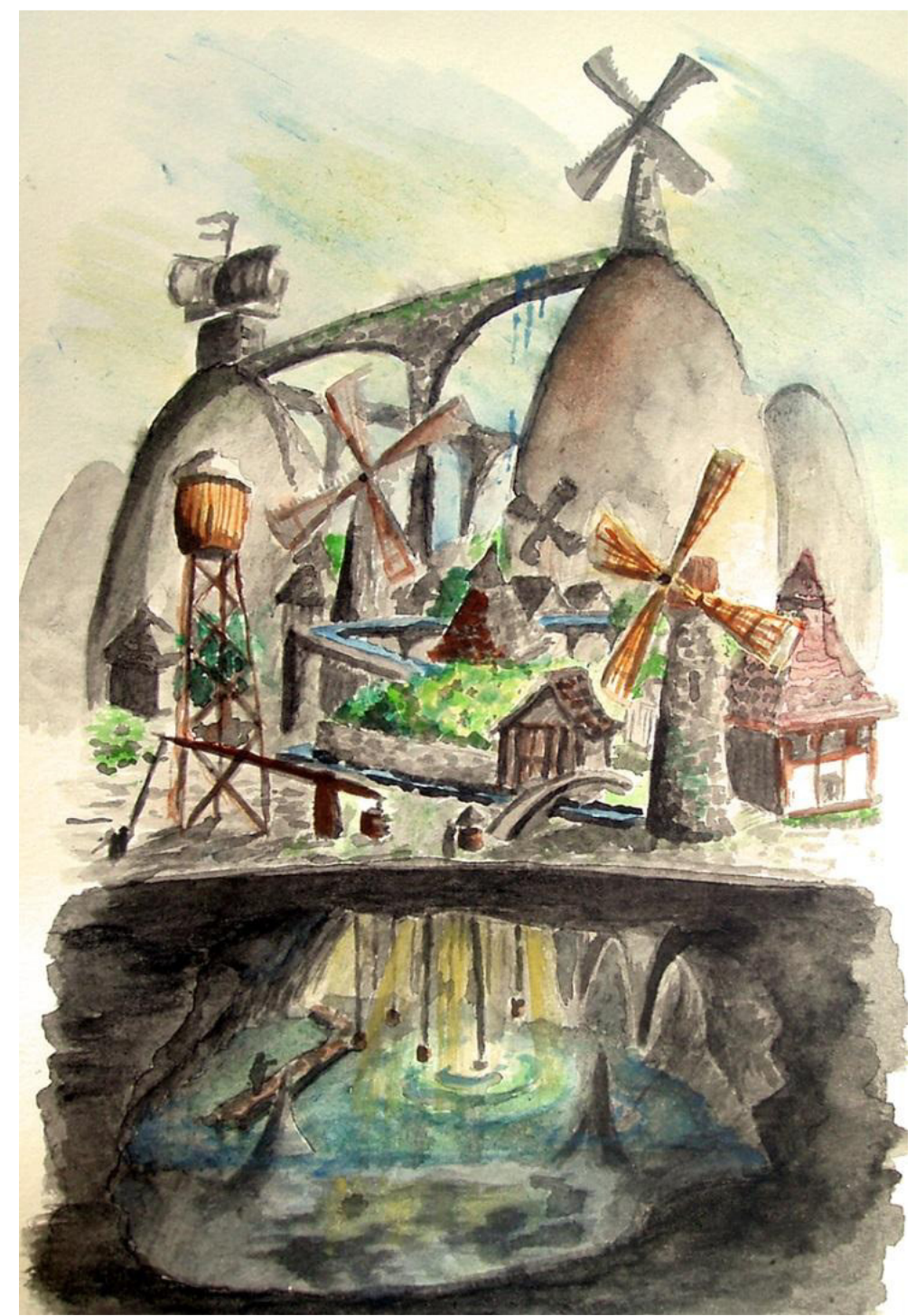

Fonte: Lutero Pröscholdt. Isaura. Disponível em: <http://ascidadesvisitadas.blogspot.com.br> Acesso em: 27/jan/2016.

Presume-se que Isaura, cidade dos mil poços, esteja situada em cima de um profundo lago subterrâneo. A cidade se estendeu exclusivamente até os lugares em que os habitantes conseguiram extrair água escavando na terra longos buracos verticais: o seu perímetro verdejante reproduz o das margens escuras do lago submerso, uma paisagem invisível condiciona a paisagem visível, tudo o que se move à luz do sol é impelido pelas ondas enclausuradas que quebram sob o céu calcário das rochas. (CALVINO, 2005, p. 24) 
A figura 1 é uma leitura do trecho acima. Para Calvino, Isaura é uma $\mathrm{d} A s$ Cidades Delgadas. Na pintura, a interpretação do artista sugere ligações verticais na cidade, profundidade e superfície em interação. O perímetro verdejante cuja fonte está no lago submerso: vida que vem da água. Pröscholdt mostra a parte submersa, mais escura, com molduras que enclausuram os movimentos da água. Contudo, esta energia move tudo o que está na superfície. Uma paisagem invisível condiciona a paisagem visível.

Figura 2: Ândria.

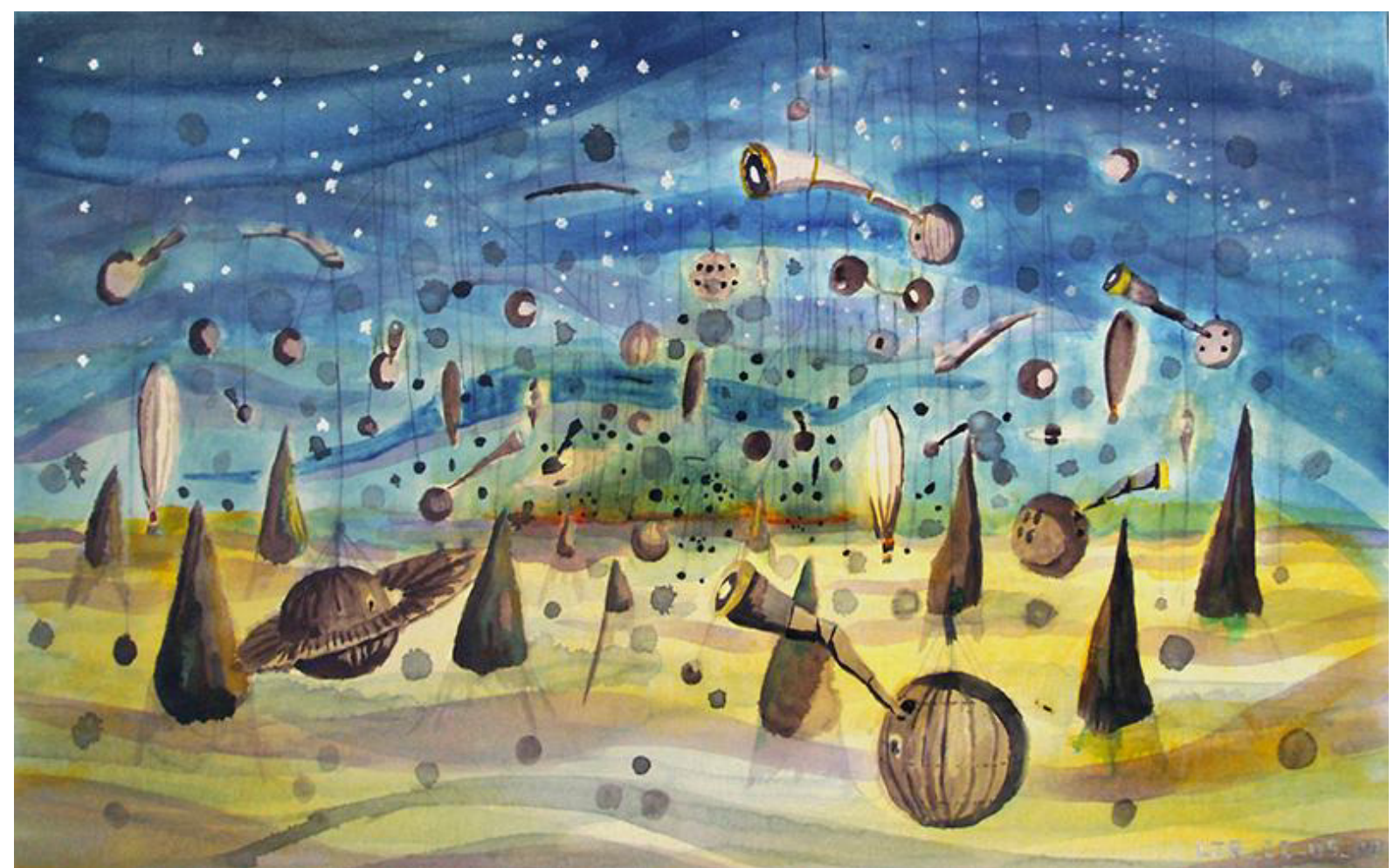

Fonte: Lutero Pröscholdt. Ândria. Disponível em:

<http://ascidadesvisitadas.blogspot.com.br/2015/09/andria_22.html> Acesso em: 28/jan/2016.

A correspondência entre a nossa cidade e o céu é tão perfeita responderam [os moradores] -, que cada mudança em Ândria comporta alguma novidade nas estrelas. - Os astrônomos perscrutam com os telescópios depois de cada mudança que acontece em Ândria e assinalam a explosão de uma nova, ou a passagem do laranja para o amarelo de um ponto remoto do firmamento, a expansão de uma nebulosa, a curvatura de uma espiral da Via Láctea. Cada mudança implica uma cadeia de outras mudanças, tanto em Ândria como nas estrelas: a cidade e o céu nunca permanecem iguais. (CALVINO, 2005, p. 137)

A figura 2 é uma leitura do trecho acima. Para Calvino, Ândria figura entre As Cidades e o Céu. Na pintura, a interpretação do artista sugere uma cidade suspensa, como se os habitantes de Ândria não vivessem com os pés no chão. Há, em Ândria, ruas suspensas e a temporalidade é outra: "a vida da cidade flui com a calma do movimento dos corpos celestes e adquire a necessidade dos fenômenos não sujeitos ao arbítrio humano" (CALVINO, 2005, p. 136). Ainda segundo Calvino,

Estudos Geográficos, Rio Claro, 15(1): 44-61, jan./jun. 2017 (ISSN 1678-698X) http://www.periodicos.rc.biblioteca.unesp.br/index.php/estgeo 
são duas as virtudes dos andrianos: a confiança em si mesmos e a prudência. Sabedores dos vínculos estreitos entre a cidade e o céu, antes de qualquer decisão sobre inovações na cidade, eles calculam os riscos e as vantagens tanto para eles próprios, para a cidade como um todo e para os outros mundos. Porque tantos são os mundos possíveis.

Figura 3. Diomira

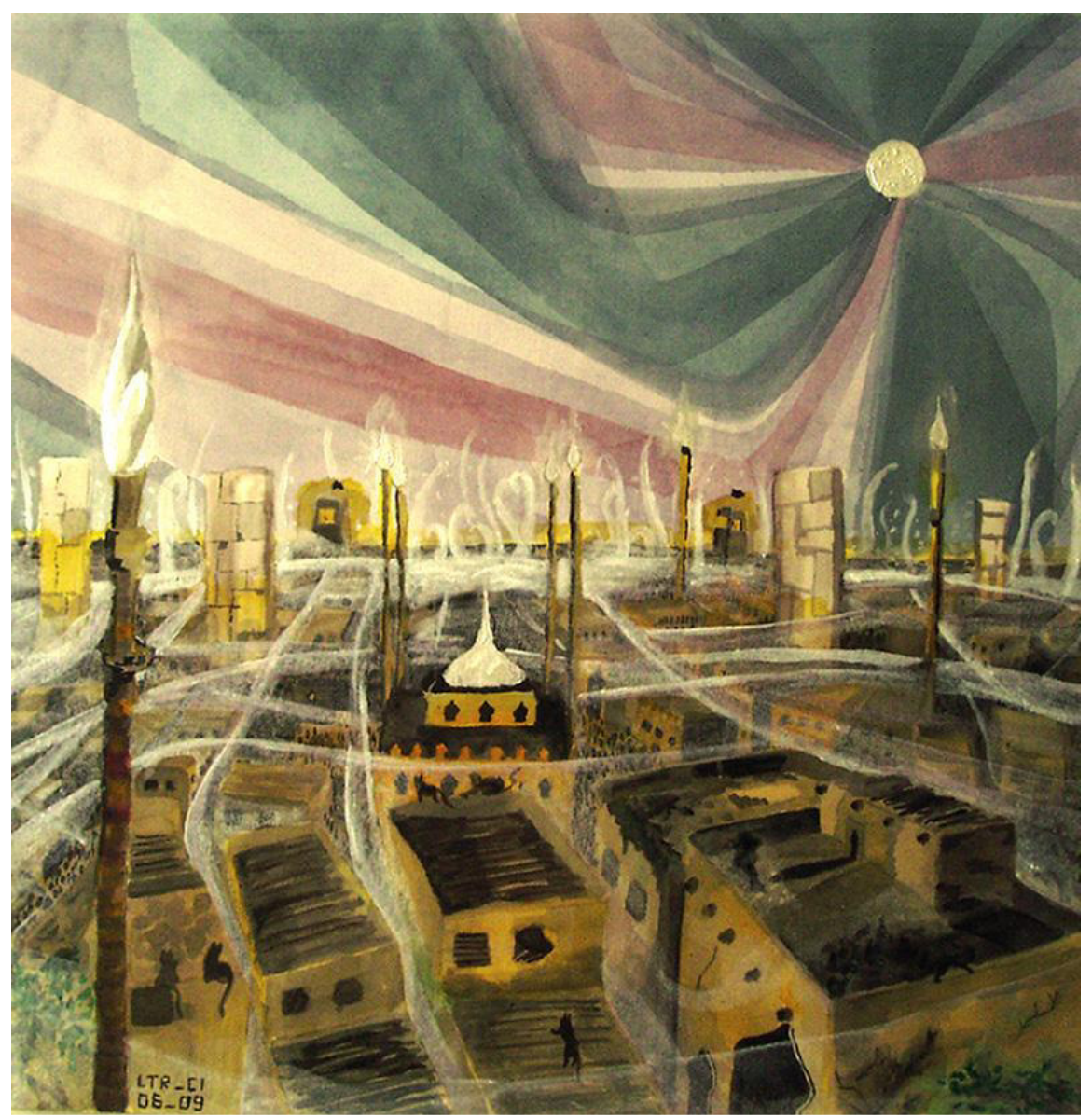

Fonte: Lutero Pröscholdt. Diomira. Disponível em:

<http://ascidadesvisitadas.blogspot.com.br/2015/09/diomira-acrylic-painting-on-canvas.html> Acesso em: 28/jan/2016.

Partindo dali e caminhando por três dias em direção ao levante, encontra-se Diomira, cidade com sessenta cúpulas de prata, estátuas de bronze de todos os deuses, ruas lajeadas de estanho, um teatro de cristal, um galo de ouro que canta todas as manhãs no alto de uma torre. Todas essas belezas o viajante já conhece por têlas visto em outras cidades. Mas a peculiaridade desta é que quem chega numa noite de setembro, quando os dias se tornam mais curtos e as lâmpadas multicoloridas se acendem juntas nas portas das tabernas, e de um terraço ouve-se a voz de uma mulher que grita: uh!, é levado a invejar aqueles que imaginam ter vivido uma noite igual a esta e que na ocasião se sentiram felizes. (CALVINO, 2005, p. 11)

Estudos Geográficos, Rio Claro, 15(1): 44-61, jan./jun. 2017 (ISSN 1678-698X) http://www.periodicos.rc.biblioteca.unesp.br/index.php/estgeo 
A figura 3 é uma leitura do trecho acima. Para Calvino, Diomira figura entre $A s$ Cidades e a Memória. De acordo com o texto, trata-se de uma cidade rica, com muitas cúpulas de prata e estátuas de bronze e até um galo de ouro que canta todas as manhãs. Diomira parece igual a outras cidades mas, durante as longas noites de setembro e ao som (que mais parece um gemido) da mulher, o viajante sente algo. Tais afetos têm força para mobilizar afectos, marcas subjetivas, memórias de felicidade. Na pintura, a interpretação do artista sugere movimento na cidade a partir da definição de linhas contornando os prédios, circulando-os. Algumas linhas podem sugerir que o vento circula nas ruas. E mesmo o brilho da lua parece obedecer ou provocar essa vontade de movimento em Diomira, a cidade que igualmente brilha. Observamos num segundo plano da tela, uma espécie de coração que parece ser de fumaça. Algo estaria pegando fogo. Ou alguém? Corpo ou corpos, o que estaria aquecido? Essas tantas linhas que sugerem o movimento na cidade também podem ser linhas de força circulando entre as formas retas dos prédios, torres e ruas. Forças que dão contorno às formas e, simultaneamente, formas que dão contornos a forças. Pensamos nas relações entre rio e margem, nessas modulações, nesse fazer e ser feito numa relação em mútua implicação.

Como dito anteriormente acerca das Cidades Invisíveis, Marco Polo é um viajante. Sua vida é andar pelo império e narrar a Kublai Khan as cidades visitadas. O livro fala de movimentos. Em que medida Marco Polo descreve as cidades visitadas? Em que medida o viajante fala de subjetividades? Marco Polo transita pelo território do Império ou por territórios existenciais? Ou ambos? Ele mergulha em interiores, observa a duplicidade de imagens refletidas e fala de desejos. Seria este último o grande disparador de tanto movimento?

No livro, todas as cidades invisíveis possuem nomes femininos. Além disso, as cidades e outras produções humanas se confundem intencionalmente: A cidade e a memória, a cidade e o desejo, a cidade e os símbolos, a cidade e as trocas, as cidades e o céu, a cidade e os mortos dentre outras. Isaura é uma cidade delgada, Ândria é uma cidade e o céu, Diomira é uma cidade e a memória. Isaura, apesar de delgada, possui ligações permanentes com a profundidade; Ândria tem ligações com o cosmo; e Diomira tem relações com o passado.

As cidades, como os sonhos, são construídas por desejos e medos, ainda que o fio condutor de seu discurso seja secreto, que as suas regras sejam absurdas, as suas perspectivas enganosas, e que todas as coisas escondam uma outra coisa. [...] As cidades também acreditam ser obra da mente ou do acaso, mas nem um nem o outro bastam para sustentar suas muralhas. De uma cidade, não aproveitamos as suas sete ou setenta maravilhas, mas a resposta que dá às nossas perguntas. (CALVINO, 2005, p. 44)

Podemos pensar com o tema da saudade presente no cancioneiro popular e o tema da memória presente nas cidades invisíveis algumas relações. Se considerarmos que o desejo produz movimento e o medo, por exemplo, interdita movimentos, tanto um quanto o outro acontecem sobre um chão. E a cidade é esse chão sobre o qual o trânsito acontece. Como percebemos nas canções, há uma cidade que o sujeito carrega consigo nos seus trânsitos pelo mundo. As canções indicam que o sujeito não deixou sua terra natal meramente por uma escolha sua. $O$ sujeito deixa a terra natal forçado pela necessidade, premido pela violência do 
capitalismo. Se pudesse, se o cardápio de possibilidades fosse mais diverso, talvez conhecêssemos outras histórias.

Estar numa cidade como vítima certamente marca interdições nos movimentos de produção de uma relação afetiva com ela. Estar na cidade nessa condição de sujeito determinado por este ambiente urbano é diferente de estar na cidade numa condição de poder assumir esse espaço como situação. Nesta situação o sujeito atua na produção do espaço na medida mesma em que produz a si mesmo, se produz como sujeito outro superando uma relação de tutela em relação às instituições, à prefeitura por exemplo. Entendemos que a reinvenção do espaço dependa do sujeito. Mas como se envolver com uma cidade se uma cidade invisível ainda determina o sujeito? Como criar um envolvimento efetivo com a reinvenção da cidade se a saudade, se a memória determina o sujeito e, de alguma maneira, impede ou dificulta muito os seus movimentos? Já que falamos em canções, como o sujeito pode fazer um acerto neste compasso?

É sujeito e temporalidade: o passado da cidade que ficou para trás, o presente nesta cidade e o futuro que é a relação com o sonho alimentado no estando aqui e agora. Forçado por um modo de vida que o obriga a procurar trabalho noutra cidade, forçado por um capitalismo que produz um sujeito e, neste processo violento de digamos sequestro subjetivo, se produz entre outras coisas, desamparo e desespero. Então é necessário fazer um acerto de contas com o passado de forma a produzir novos vínculos com a memória, elaborar esse sentimento de retirada violenta da terra original superando o trauma, transformandoo em potência e, desta maneira, criar outros vínculos na ligação do sujeito com a cidade atual. Para que o sujeito descubra, crie ou conquiste um outro jeito de estar na cidade. Estamos evidentemente falando da relação entre sujeito e mundo, aqui materializado num lugar específico denominado cidade. Portanto, um lugar das lembranças, um lugar afetivo que podemos denominar 'terra natal' de onde formos forçados a sair, e um lugar real que é esta cidade que nos permite sobreviver diante desta dura realidade.

\section{Cidade subjetiva, Topofilia, Cidade rebelde, Cidade por projeto.}

Já no início da década de 1990, Guattari (1992) afirmava que as distinções entre cidade e natureza estavam a esmaecer. Todos os espaços estariam, num tempo breve, determinados pelas cidades, o que nos leva a pensar que os espaços produzidos e/ou utilizados para fins de lazer, esporte turismo e mesmo as reservas ecológicas estavam confinados como mercadoria. A imensa maioria da população mundial estaria vivendo nas cidades e, mesmo a pequena parte restante, estaria determinada pelo habitat urbano. Percebemos, observando as cidades, uma espécie de separatismo interno por muralhas equipadas tecnologicamente, fortificações urbanas demarcando o território, marcando as classes sociais, impedindo a circulação, criando espaços privados coletivos e guetos.

Enfim, a artificialização dos encontros. Ao mesmo tempo em que diluem as diferenças internas, reduzem os encontros nas cidades meramente entre diferenças desiguais. Interessante perceber neste ponto uma relação com o levantamento histórico das cidades presente em Topofilia de Yi-fu Tuan (2012), quando este recupera a origem das cidades, relata as muralhas separando a cidade do campo bem como as relações a as características das pessoas e dos encontros que acontecem dentro e fora das muralhas, portões e portais.

Estudos Geográficos, Rio Claro, 15(1): 44-61, jan./jun. 2017 (ISSN 1678—698X)

http://www.periodicos.rc.biblioteca.unesp.br/index.php/estgeo 
Para Guattari, não existe mais uma capital dominando a economia mundial. O que existe é um arquipélago de cidades, subconjuntos de grandes cidades que se ligam com os recursos da tecnologia tornando-as conectadas, extremamente próximas apesar da distância física entre elas, algo que ele chama de um rizoma multipolar urbano planetário. Como se um capitalismo inteligente devido ao avanço das tecnologias, ligasse os imensos bolsões de pobrezas, focos urbanos altamente desenvolvidos, campos fortificados habitados pelo poder. Como se as diferenças na cidade estivessem agora transitando, se trombando, se atravessando apenas no âmbito da circulação do mercado global.

As cidades são imensas máquinas (...) produtoras de subjetividade individual e coletiva. O que conta, com as cidades de hoje, é menos os seus aspectos de infraestrutura, de comunicação e de serviço do que o fato de engendrarem, por meio de equipamentos materiais e imateriais, a existência humana sob todos os aspectos em que se queira considerá-las. Daí a imensa importância de uma colaboração, de uma transdiciplinaridade entre os urbanistas, os arquitetos e todas as outras disciplinas das ciências sociais, das ciências humanas, das ciências ecológicas etc... (Guattari, 1992, p.152)

É necessário, portanto, recolocar em discussão o atual espírito de competição econômica entre empresas e nações, revisão da industrialização, da emissão de poluentes, da circulação, rever todo um modo de vida atual. Percebemos com Félix Guattari e Yi-fu Tuan que estão diluídas, praticamente não existem mais, separações entre cidade e campo, ou cidade e natureza. A força subjetiva das cidades como materialização de um modo de vida fez com que tanto ambientes construídos como ambientes naturais produzam formas de pensamento muito parecidas. Ou seja, o modo de vida contemporâneo está determinado por uma urbanidade que tem colocado em risco todas as formas de vida sobre a Terra.

Neste horizonte de catástrofe ambiental, novas formas de subjetividade individual e coletiva se fazem urgentes e, nesta perspectiva, várias áreas do saber nas ciências sociais e humanas podem produzir coletivamente outros sentidos para a cidade. Ela não pode mais ser definida apenas no seu caráter de espacialidade visto ser a cidade o cruzamento das questões econômicas, sociais, culturais. Tratase, portanto, da questão prioritária na agenda atual. Contudo, apesar de a cidade produzir o destino da humanidade, constata-se um desconhecimento desse aspecto global das problemáticas urbanas como meio de produção da subjetividade.

As cidades não podem ser vistas apenas como mercadoria. As escolhas sobre o que fazer neste chão, de como fazer neste chão, tais decisões e demarcações não podem ficar apenas ao sabor das decisões resultantes dos interesses econômicos e imobiliários. Pensamos com o documentário Bike versus Carros $^{12}$ (2015) que a configuração das cidades é resultado do jogo de forças que a produzem. Por exemplo, uma cidade que prioriza a circulação dos automóveis, ou seja, uma cidade resultado dos interesses econômicos da indústria automobilística ou dos interesses da exploração do petróleo ganha necessariamente uma configuração urbana diferente da cidade que prioriza o uso das modalidades de transporte não poluentes ou de transporte coletivo sobre trilhos.

\footnotetext{
${ }^{12} \mathrm{O}$ documentário mostra como a indústria automobilística (do petróleo) influencia políticas públicas nas cidades, orienta os investimentos públicos e produz configurações na cidade. E comparação com cidades que estimulam o uso de modais não poluentes como a bicicleta. Filmado em São Paulo, Los Angeles, Toronto e Copenhague e depoimentos da professora Raquel Rolnik.
}

Estudos Geográficos, Rio Claro, 15(1): 44-61, jan./jun. 2017 (ISSN 1678-698X)

http://www.periodicos.rc.biblioteca.unesp.br/index.php/estgeo 
No período entre 2013 e 2016, a cidade de São Paulo trouxe à luz um intenso debate acerca do investimento público em ciclovias. Vários setores se levantaram contra esta política, chegando a paralisar as obras por exigência do Ministério Público Estadual que questionava, entre outras coisas, os valores do investimento em ciclovias e ciclo-faixas além de solicitar um estudo detalhado de demanda para o uso de bicicletas. Pois bem, como estimar as demandas por um tipo de circulação na cidade quando sua estrutura física e urbana não oferece praticamente nenhuma opção para esta modalidade de transporte? E seriam os valores gastos para instalação dessa infraestrutura superiores aos valores exigidos pela circulação de carros nas marginas, nas obras de arte como pontes e viadutos e etc?

Com este rápido exemplo, concordamos com as afirmações de que pensar a cidade significa necessariamente pensar também o sujeito. Sujeito e cidade, cidade e sujeito se implicam mutuamente.

A questão do tipo de cidade que queremos não pode ser separada da questão do tipo de pessoas que queremos ser, que tipos de relações sociais buscamos, que relações com a natureza nos satisfazem mais, que estilo de vida desejamos levar, quais são nossos valores estéticos. O direito à cidade é, portanto, muito mais do que um direito de acesso individual ou grupal aos recursos que a cidade incorpora: é um direito de mudar e reinventar a cidade mais de acordo com nossos mais profundos desejos. Além disso, é um direito mais coletivo do que individual, uma vez que reinventar a cidade depende inevitavelmente do exercício de um poder coletivo sobre o processo de urbanização. A liberdade de fazer e refazer a nós mesmos e a nossas cidades é um dos nossos direitos humanos mais preciosos, ainda que um dos mais menosprezados..." (Harvey, 2014, p. 28).

Daí ser nossa época ao mesmo tempo aterrorizante e potente. Pensemos um pouco em nossa pele. Ela é plástica, ela dobra, estica, ela é uma superfície plástica que responde aos estímulos. Ela se move com os estímulos de dentro, com a contração e relaxamento dos músculos. Ela também responde aos estímulos de fora, enruga com a água, responde às variações da temperatura, da umidade e da pressão. Ela faz uma fronteira entre o dentro e o fora. Consideremos também a casa como pele. Menos plástica, ela também faz a fronteira entre dentro e fora. Pensemos o corpo em interior e exterior. Pensemos a casa como abrigo, aconchego. E igualmente a cidade como casa de um corpo social, como abrigo, como uma espécie de morada social que é construída, desconstruída e reconstruída constante e coletivamente. A cidade como resultado de um jogo de forças, resultado de interesses, de capitais que, em trânsito, se fixam no território (e se desterritorializam).

Desta forma, queremos pensar também que sujeito e mundo não estejam dados a priori. Sujeito e mundo se constituem nesta relação dentro e fora, ou na relação entre eles, uma espécie de inter-relação. Desta maneira, podemos pensar a cidade como obra aberta, uma obra que muda com as mudanças da sociedade. Uma obra coletiva habitada pelos corpos, de onde se extrai a sobrevivência. A cidade é, em parte, sustentadora da vida. A cidade é onde corpos e coisas se cruzam e se produzem.

Pensemos a pele de um corpo como o limite entre o dentro e o fora. Dentro estão as forças e as intensidades internas, as evidências da consciência e as Estudos Geográficos, Rio Claro, 15(1): 44-61, jan./jun. 2017 (ISSN 1678-698X) http://www.periodicos.rc.biblioteca.unesp.br/index.php/estgeo 
profundezas a serem descobertas no campo das emoções e dos sentimentos, o que vamos chamar grosso modo de inconsciência. E o externo compreendido como os atravessamentos em nosso corpo considerados como a relação com o mundo, com a política, com o jogo de forças presente no corpo social. A casa como a moradia do corpo e a cidade, por conseguinte, como a casa de um corpo social. A cidade enquanto pele de um corpo social pode estar, da mesma maneira, mais ou menos impermeável às sensações e afetos, mais ou menos permeável a atravessamentos desta ou daquela ordem. Uma cidade projetada (ou não) mas construída para os carros, para as moradias seriadas, produz necessariamente corpo e corpos mais ou menos abertos para os encontros. É necessário pensar um devir social na cidade.

Contudo, como se dá a implicação desses corpos na produção da cidade? Guattari fala da importância de ressingularizar as finalidades da atividade humana. Ao se referir aos subúrbios, Yi-Fu Tuan aponta as especificidades dessa implicação. O subúrbio está na fronteira da expansão metropolitana. É uma sociedade em formação, ao final do qual está a cultura urbana. As características pioneiras do novo subúrbio manifestam-se em sua falta de forma (porque gênese, nascimento, algo de novo, pensando com Hannah Arendt (1992), um novo início no mundo e toda potência que a novidade carrega), falta de uma estrutura social diferenciada e na primitivez de suas condições de vida: ruas lamacentas, abastecimento de água incerto, sistemas primitivos de esgoto de lixo, escolas deficientes ou inexistentes, transporte precário e uma sensação de isolamento. É necessário um espírito pioneiro (e isso é positivo), no sentido de ser autossuficiente, quando uma família se muda para um distrito pobre, criado - quase do dia para a noite - no campo, também se necessita de um espírito de cooperação com os vizinhos que estão passando pelos mesmos apuros. Nos subúrbios mais pobres, os residentes frequentemente constroem suas próprias casas com as suas próprias ferramentas.

Eles têm que aprender as habilidades do pioneiro faz-tudo. O suburbano de classe média, por sua vez, pode se mudar para uma casa já "terminada", mas ainda há muito trabalho a ser feito, o que obriga a desempenhar o papel de "faz-tudo". Este papel pode ser assumido prazerosamente, normalmente dá mais status ao pai e fortalece sua imagem de provedor da família. De qualquer modo, não é um papel que ele possa assumir no apartamento quase lotado da cidade onde qualquer mudança na estrutura necessita a aprovação do proprietário. Na casa do subúrbio, um homem realmente pouco pode fazer para modificar os seus arredores, mas a possibilidade, simbolizada pela oficina bem equipada, aí está. A cooperação é um outro traço da fronteira suburbana. Necessidades comuns engendram ajuda mútua. Existe uma força, não a do centro, mas a das pontas, das bordas, das extremidades da cidade, uma potência, a do subúrbio.

Queremos colocar ainda um pouco mais de luz nesta figura do faz-tudo. Compreendemos nesta figura uma espécie de potencial criativo, aquele que no seu fazer, na sua prática, faz da casa, dos subúrbios e, portanto, do mundo uma por assim dizer oficina, um laboratório de experimentação. Talvez seja sua necessidade vital na dimensão da sobrevivência que o empurra a criar outras possibilidades, novas formas, outras obras. O faz-tudo suburbano pode ser associado ao artista diante de uma tela em branco, ao escritor diante de uma folha em branco, ao compositor com seu instrumento às mãos. Uma necessidade vital o empurra ao trabalho criativo. Afirmamos ser o subúrbio a tela e a tinta para a criação da obra. Os subúrbios contribuem para pensarmos a cidade como obra aberta. 
Retomando a questão do acerto do compasso, vamos com Luc Boltanski e Ève Chiapello (2009) trabalhar a formação da cidade por projetos. Afirmando não ser esta uma crise do capitalismo e sim uma crise da crítica ao capitalismo, estes autores traçam o perfil do novo espírito do capitalismo analisando os textos de gestão empresarial nos anos de 1960 e 1990 e chegam à ideia de cidade por projetos inserida num mundo concebido em rede, essa nova forma de conexão que já não depende mais do espaço, e sim do tempo. Tais autores trabalham a cidade a partir da lógica industrial, doméstica, mercantil, cívica, de rede, inspirada e lógica da fama.

A cidade como projeto aparece com as transformações e reconfigurações nessas lógicas, o que os autores chamam de mundos. Percebemos o crescimento significativo da lógica da rede na atualidade e o declínio da lógica doméstica e da lógica cívica. A leitura de o novo espírito do capitalismo reforça nosso pensamento acerca da configuração das cidades vinculada aos valores e modos de vida do seu tempo. A proeminência da lógica das redes reforça o que já discutimos acima com a desterritorialização.

O projeto é a oportunidade e o pretexto para a conexão. Ele reúne temporariamente pessoas muito diferentes e apresenta-se com um segmento de rede fortemente ativado durante um período relativamente curto, mas que permite criar laços mais duradouros, que permanecerão adormecidos, mas sempre disponíveis. Os projetos possibilitam a produção e a acumulação num mundo que, se fosse puramente conexionista, conheceria apenas fluxos, sem que coisa alguma pudesse estabilizar-se, acumular-se ou ganhar forma: tudo seria carregado pela corrente incessante dos contatos estabelecidos, que, em vista de sua capacidade de comunicar tudo com tudo, distribuem e dissolvem incessantemente aquilo que cai em suas malhas. O projeto é precisamente um amontoado de conexões ativas capazes de dar origem a formas, ou seja, dar existência a objetos e sujeitos, estabilizando e tornando irreversíveis os laços. Portanto, é um bolsão de acumulação temporário que, sendo criador de valor, dá fundamento à exigência de ampliar a rede, favorecendo conexões. (BOLTANSKI; CHIAPELLO, 2009, p 135)

$\mathrm{Na}$ medida em que a noção de justiça distributiva da riqueza produzida na cidade se transforma, as relações humanas vão ganhando novos valores sociais e éticos, a cidade vai ganhando uma materialidade que favoreça tais relações e encontros. As conexões assumem mais fluidez, mais leveza na medida em que não se fixam, pelo contrário, circulam. A manipulação dos símbolos vai produzindo as imagens e os valores mais interessantes e sempre coerentes com a lógica do capitalismo no seu tempo. E, nesta medida, o capitalismo vai capturando, vai se apropriando das forças sociais em seu favor. Entram em cena e ganham proeminência, os líderes e suas visões. O empreendedor, por exemplo, ou o sujeito de sucesso e de fama vão produzindo sentidos a serem compartilhados. Essa lógica, que aponta para o futuro como se o sucesso na vida dependesse de um sucesso profissional vai (digamos assim) colonizando os pensamentos e projetando no tempo, lançando para o futuro a produção de um modo de viver único e, sendo único, inquestionável.

De acordo com esses autores, toda uma engenharia do pensamento foi se constituindo nas últimas décadas para formação de uma classe de engenheiros,

Estudos Geográficos, Rio Claro, 15(1): 44-61, jan./jun. 2017 (ISSN 1678-698X)

http://www.periodicos.rc.biblioteca.unesp.br/index.php/estgeo 
empresários, homens de negócios, executivos que ascendem aos postos de comando e gerência no mundo empresarial, um conjunto de formações acadêmicas e pesquisas seguem validando tais produções de verdades que funcionam como um imã para o pensamento na sociedade. O novo espírito do capitalismo vai permeando o conjunto das representações mentais e colonizando o pensamento geral. Uma falsa leveza nos trânsitos do sujeito pelo mundo e uma nova impermeabilidade da pele aos encontros (que ganham a mediação por equipamentos de informática nas infovias e redes sociais) reconfigurados, vão reduzindo as subjetividades apenas ao seu aspecto de consumidores.

A empresa privada concorrencial continua sendo considerada mais eficaz e eficiente do que a organização não lucrativa (mas isso tem o preço não mencionado de transformar o amante da arte, o cidadão, o estudante, a criança em relação a seus professores, o beneficiário de ajuda social... em consumidor), e a privatização e a mercantilização máximas de todos os serviços mostram-se como as melhores soluções do ponto de vista social, pois reduzem o desperdício de recursos e obrigam a antecipar-se às expectativas dos clientes. (BOLTANSKI; CHIAPELLO, 2009, p 45.)

Progresso material, eficácia e eficiência na satisfação das necessidades, modos de organização social favoráveis ao exercício das liberdades econômicas e compatíveis com os regimes políticos liberais são os pilares que justificam esse espírito do capitalismo apresentado pelos autores.

\section{Cidade mulher}

Moacyr Luz é um sambista carioca nascido em 1958. Na canção Beleza em diamante, parceria com o também sambista Sereno (Jelsereno de Oliveira, carioca nascido em 1952) e interpretada com Mart'nália (Martinália Mendonça Ferreira, carioca nascida em 1965, cantora, atriz, compositora, percussionista), aparece como em outras canções, essa ligação entre a dimensão do feminino e a cidade:

\section{O meu samba é pra quem quiser \\ Usar da mesma inspiração \\ Cidade mulher, um bem-me-quer \\ No coração. \\ Um cantar de fé pra quem quiser \\ Usar da mesma inspiração \\ Cidade mulher, um bem-me-quer \\ No coração.}

Conversamos com Moacyr Luz algumas vezes. Caminhamos juntos por algumas ruas do Rio de Janeiro. Este artista brasileiro é apaixonado por sua terra natal. Apesar de sua andança pelo Brasil e pelo mundo no trabalho de levar sua arte para o público, sua casa é a capital fluminense e esta paixão pela terra natal é muito presente em sua obra, tanto nas canções como na literatura. Sua relação com a cidade é matéria prima do seu trabalho criativo. Atento, o artista explora a potência dos encontros, as histórias produzidas pelas pessoas comuns nesta convivência nas

Estudos Geográficos, Rio Claro, 15(1): 44-61, jan./jun. 2017 (ISSN 1678-698X) http://www.periodicos.rc.biblioteca.unesp.br/index.php/estgeo 
ruas, nas esquinas, nas praças, nas rodas de samba, nos terreiros, nos bares, nas festas, na celebração da vida que pulsa na cidade. Na cidade viva.

Interessante pensar com este sambista tijucano Moacyr Luz, com Ítalo Calvino dentre outros, a dimensão do feminino (e do masculino) e a cidade, as relações de alteridade, eu e outro, as relações com o outro, tudo isso no chão da cidade. No chão mas também na subjetividade, na produção da subjetividade. A areia que cai na ampulheta, o tempo que passa como o rio fluindo para o mar; $A$ inexorável outra idade, a outra cidade: a produção do sujeito e a produção da cidade. Sujeito outro, cidade outra. A abertura das possibilidades, os possíveis outros e, na mesma medida, de cidades outras.

Ainda com Ítalo Calvino e Lutero Pröscholdt, na tela abaixo encontramos as leituras do artista a partir de Irene, uma cidade invisível.

Figura 4: Irene

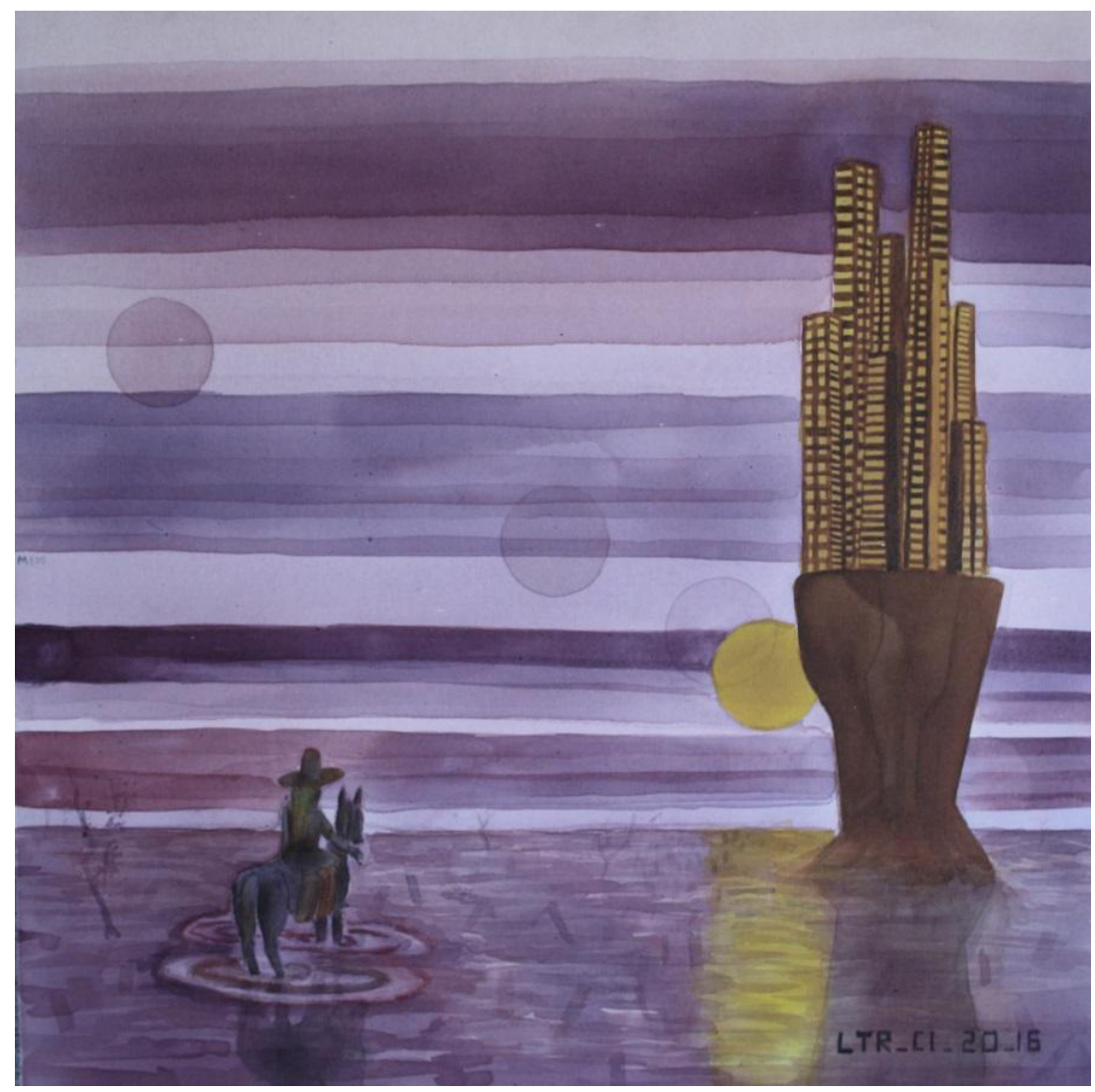

Fonte: Lutero Pröscholdt. Irene. Disponível em:

<https://www.facebook.com/invisiblecitiessketches/photos/a.331755686959580.1073741826.3315062 33651192/727289254072886/?type=3\&theater $>$ Acesso em: 25/dez/2016.

A esta altura, Kublai Khan espera que Marco diga como é Irene vista de dentro. E Marco não pode fazê-lo: não conseguiu saber qual é a cidade que os moradores do planalto chamam de Irene; por outro lado, não importa: vista de dentro, seria uma outra cidade; Irene é o nome de uma cidade distante que muda à medida que se aproxima dela. (CALVINO, 2005, p. 114)

A figura 4 é uma leitura do trecho acima. Para Calvino, Irene figura entre As Cidades e o Nome. De acordo com o texto, trata-se de uma cidade que se revela de Estudos Geográficos, Rio Claro, 15(1): 44-61, jan./jun. 2017 (ISSN 1678-698X) http://www.periodicos.rc.biblioteca.unesp.br/index.php/estgeo 
diversas maneiras, a depender do ponto de vista. E considerando que esse ponto de vista também difere no mesmo sujeito, Irene é tantas cidades quanto sujeitos em devir.

É muito interessante a tela. O artista parece sugerir que o sol está em movimento, o que nos leva a pensar que o observador está a observar Irene há algum tempo. Este, por sua vez, nos remete aos tantos sertanejos das canções populares citadas neste estudo. Podemos compreender o sertanejo, o forasteiro, 0 andarilho, assim como o aventureiro, o artista, o educador e o político apaixonados, migrando pelo mundo. Estão em movimento sobre o chão mas também vivem o movimento dentro de si. O cavalo parece parado, mas algum relevo na superfície lisa da água sugere haver algum movimento. Quanto à cidade edificada sobre um platô, vertical, íngreme, quase inacessível, esta muda com as mudanças do olhar e do observador.

A cidade de quem passa sem entrar é uma; É outra para quem é aprisionado e não sai mais dali; Uma é a cidade à qual se chega pela primeira vez, outra é a que se abandona para nunca mais retornar; Cada uma merece um nome diferente; Talvez eu já tenha falado de Irene sob outros nomes; Talvez eu só tenha falado de Irene. (CALVINO, 2005, p. 115)

Pensemos nos moradores de Irene. Se esta se mostra inacessível, estar em Irene parece significar estar aprisionado em Irene. Queremos, neste ponto, relacionar Irene com as prisões subjetivas, aquelas que capturam nossos pensamentos. Irene está para 'o vazio da modernidade exangue' de Guattari (1992). Associamos Irene ao falso nomadismo e, portanto, escapar de Irene é como aproveitar as brechas existentes nas idealizações para aceder ao verdadeiro nomadismo como dos índios da América pré-colombiana, este verdadeiro nomadismo compreendido como o desejo, neste caso, o desejo de uma vida melhor na cidade, desejo este construído e sustentado nos encontros, sustentados num movimento coletivo. A cidade pode ser, como experimentamos no Orçamento Participativo, um bom motivo, uma espécie de 'pretexto' para manter vivo, para sustentar (no sentido de dar suporte) para um movimento coletivo, para manter os encontros dos corpos numa ação coletiva, num fazer com o outro e, em mútua implicação, dum fazer-se outro. Pensamos a cidade como construção permanente, e o direito à cidade não como algo dado a priori mas como construção coletiva.

Queremos pensar a cidade numa perspectiva de experiência, deslocando de uma racionalidade dada para uma experimentação, uma invenção do espaço de forma a superar o sofrimento de estar na cidade na medida em que se produz um sentido de estar nela. Estar na cidade determinado por um passado ou por um sofrimento nos parece limitar os movimentos, ao passo que estar situado na cidade ocupando um espaço e um tempo cujo significado está de certa forma produzido pelo sujeito, nos parece disparador de movimento. Ou seja, assumir-se na cidade, assumi-la e produzi-la. Sujeito e espaço produzindo-se na mútua implicação.

\section{Considerações Finais}

A singularidade "cidade de Suzano" e os encontros com sua população nas centenas de reuniões e nas cerca de 40 grandes plenárias nos colocaram em

Estudos Geográficos, Rio Claro, 15(1): 44-61, jan./jun. 2017 (ISSN 1678-698X)

http://www.periodicos.rc.biblioteca.unesp.br/index.php/estgeo 
contato direto com uma população migrante com forte presença de brasileiros afrodescendentes, de japoneses e nipodescendentes, e marcas da ancestralidade indígena expressa na paisagem urbana denominando rios, ruas, prédios, lugares. Durante os anos de 2005 e 2008 fomos percorrendo e cartografando o movimento na cidade promovido pelo Orçamento Participativo e, principalmente no trabalho com o conselho do OP, denominado CORPO, num intenso calendário de reuniões de trabalho que construíam, encontro a encontro, as decisões sobre a parcela dos investimentos no Orçamento Público Municipal e seu desdobramento em obras e serviços públicos.

A população, de alguma maneira, participando das mudanças na paisagem urbana na mesma medida em que sujeitos iam se produzindo neste processo de conhecer mais a realidade da cidade, suas diferenças, suas características, sua produção, suas peculiaridades locais, sua diversidade cultural. Procuramos sinais na cultura popular, em particular nas canções que abordam a saudade da terra natal. Passamos pela literatura de Ítalo Calvino e a leitura artística de Lutero Pröschold. Neste processo, nos encontramos com mais um artista brasileiro, Moacyr Luz. Dialogamos também com a obra teórica de Félix Guattari, Yi-fu Tuan, David Harvey, Luc Boltanski e Ėve Chiapello. Nosso referencial bibliográfico demonstra que nosso estudo registrado na dissertação de mestrado se apoia em outros autores para além dos citados neste artigo.

\section{Bibliografia}

ARENDT, Hannah. A crise na educação. In edição. São Paulo: Editora Perspectiva, 1992. Entre o passado e o futuro. $3^{a}$

BAUMAN, Zygmunt. Confiança e medo na cidade. Rio de Janeiro: Zahar, 2009. BOLTANSKI, L.; CHIAPELLO, È. O novo espírito do capitalismo. Tradução de Ivone C. Benedetti. São Paulo: Editora WMF Martins Fontes, 2009.

CALVINO, Ítalo. As cidades invisíveis. $2^{a}$ edição. São Paulo: Companhia das letras, 2005.

\section{O visconde partido ao meio}

$\overline{\mathrm{CASTR}} \mathrm{O}$, Eduardo Viveiros de. Uma boa política é aquela que multiplica os possíveis. In SZTUTMAN, Renato. Eduardo Viveiros de Castro Encontros. Rio de Janeiro: Beco do Azougue, 2008. p.228-258.

DIAS, Romualdo. Educação de jovens e adultos: novas perspectivas! Curitiba: Appris, 2015.

FREIRE, Paulo. Papel da educação na humanização. Revista Paz e Terra, São Paulo, nr. 9, p. 123-132, out. 1969.

e terra, 1987.

Pedagogia do oprimido. $11^{\text {a }}$ edição. 23ํㅡㄹ reimpressão. Rio de Janeiro: Paz

FOUCAULT, Michel. Por que investigo o poder? In DREYFUS, Hubert L. e

O que são as luzes. In Ditos \& Escritos Volume II. Rio de Janeiro:

Forense Universitária, 2000. (335-351)

GUATTARI, Félix. Restauração da cidade subjetiva. In Caosmose. Rio de Janeiro: Editora 34, 1992.

HARVEY, David. Cidades Rebeldes: do direito à cidade a revolução urbana. São Paulo: Martins Fontes, 2014. 
JULLIEN, François. A arte do desvio. In: MORIN, Edgar et al. A sociedade em busca de valores: para fugir à alternativa entre o cepticismo e o dogmatismo. Lisboa: Instituto Piaget, 1996.

LAVAL, Christian e DARDOT, Pierre. La nueva razón del mundo. Ensayo sobre la sociedade neoliberal. Barcelona: Gedisa Editorial,2013.

NIETZSCHE, Friedrich. Crepúsculo dos ídolos ou como se filosofa com o martelo. Petrópolis: Editora Vozes, 2014.

RANCIĖRE, Jacques. $O$ desentendimento. Política e Filosofia. Até página 33. São Paulo: Editora 34, 1996.

RICOEUR, Paul. Tarefas do Educador Político. São Paulo: Edições Loyola. ROLNIK, Suely. Pensamento, corpo e devir. Uma perspectiva ético/estético/política no trabalho acadêmico. In: Cadernos de Subjetividade, v.1, nr.2: 241-251. Núcleo de Estudos e Pesquisas da Subjetividade, PUC/SP. São Paulo, set/fev, 1993.

SANTOS, Boaventura de Souza. A gramática do tempo: para uma nova cultura política. São Paulo: Cortez, 2006.

Para um novo senso comum. A ciência, o direito e a política na transição paradigmática. - $A$ crítica da razão indolente. Contra o desperdício da experiência. v 1: $5^{\mathrm{a}}$ edição. São Paulo/SP: Cortez, 2000.

. Democratizar a democracia: os caminhos da democracia participativa.

Coleção Reiventar a emancipação social, vol.1. Rio de Janeiro: civilização brasileira, 2002.

SARTRE, Jean-Paul. O que é subjetividade. Rio de Janeiro: Nova Fronteira, 2015. TUAN, Yi-Fu. Topofilia: um estudo sobre a percepção, atitudes e valores do meio ambiente. Londrina: Eduel, 2012. 